\title{
Molecular Interaction Potential with Polarization (MIPp) Study of the Interplay Between Ion- $\pi$ and Hydrogen Bonding Interactions
}

\author{
David Quiñonero, Daniel Escudero, Antonio Frontera ${ }^{*}$ and Pere M. Deyà
}

Departament de Química, Universitat de les Illes Balears, Crta. de Valldemossa km 7.5, 07122 Palma, Baleares, Spain

\begin{abstract}
The interplay between cation- $\pi$ and hydrogen bonding interactions involving aromatic rings is studied by means of Molecular Interaction Potential with polarization (MIPp) calculations. We have analyzed the effect of the participation of the aromatic in hydrogen bonding interactions on the ion-binding affinity of the arene, by means of Molecular Electrostatic Potential (MEP), MIPp and ab initio calculations. We have observed that when the aromaric ring participates in hydrogen bonding interaction as hydrogen bond (HB) donor its capacity for interacting with cations (cation- $\pi$ interaction) augments. In addition when the arene is forming hydrogen bonding interactions as HB acceptors, the capacity of the aromatic ring for interacting with anion increments (anion- $\pi$ interaction). This mutual influence of cation- $\pi$ and HB interactions is studied and analyzed by means of the MIPp partition scheme.
\end{abstract}

\section{INTRODUCTION}

Non-covalent interactions are crucial in many areas of modern chemistry, especially in the field of supramolecular chemistry and molecular recognition $[1,2]$, which rely on these forces. Interactions involving aromatic rings are important binding forces in both chemical and biological systems and they have been reviewed by Meyer et al. [3]. Among them, anion- $\pi$ interactions [4-6] have attracted considerable attention in the last five years $[7,8]$. There is a great deal of experimental [9-15] and theoretical [16-19] work that evidence that the anion- $\pi$ interactions play a prominent role in several areas of chemistry, such as molecular recognition [20] and transmembrane anion transport. [21, 22] Anion coordination is an important and challenging aspect of contemporary supramolecular chemistry. Recent investigations have provided experimental evidence for the usefulness of pyridine and diazines coordinated to $\mathrm{Ag}(\mathrm{I})$ in the design of anion receptors by demonstrating the ability of these rings to interact with anions through multiple anion- $\pi$ interactions [2327]. The structural consistency displayed by these networks and the uniform mode of anion binding demonstrate the potential use of anion- $\pi$ interaction in a structurally directing role [28]. In addition, cation- $\pi$ interactions [29-34] are also important binding forces that are decisive in the ion selectivity of potassium channels $[35,36]$. They are also important for the binding of acetylcholine to the active site of the enzyme acetylcholine esterase [37], and, recently, their importance has been demonstrated in neurotransmitter receptors [38]. The cation- $\pi$ interaction is dominated by electrostatic and ion-induced polarization terms [39]. The nature of the electrostatic term can be rationalized by means of the permanent quadrupole moment of the arene. The hydrogen bond

*Address correspondence to this author at the Department of Chemistry, Universitat de les Illes Balears, Crta de Valldemossa km 7.5, 07122 Palma de Mallorca, Baleares, Spain; Tel: +34-971173498; Fax: +34-971173426; E-mail: toni.frontera@uib.es interaction is mainly dominated by electrostatic effects (dipole-dipole interactions) [40].

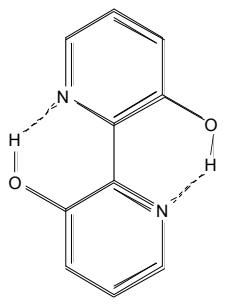

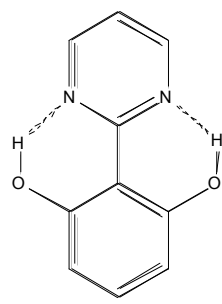

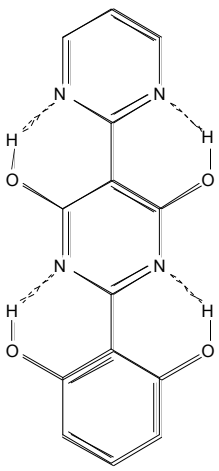

3

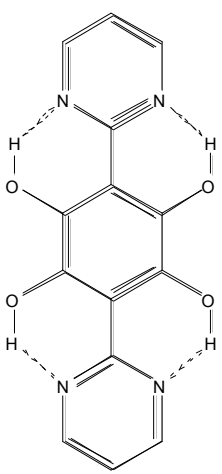

4

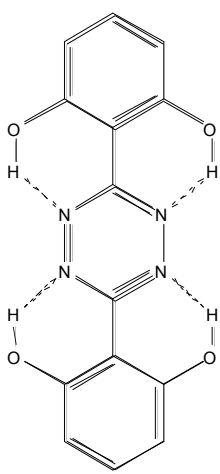

Fig. (1). Aromatic compounds 1-5, the dashed lines indicate the intramolecular hydrogen bonds.

We have recently reported experimental [41] and theoretical $[42,43]$ evidence of interesting synergistic effects between anion- $\pi$ and $\pi-\pi$ interactions. We have demonstrated that there is a remarkable interplay between anion- $\pi$ and $\pi-\pi$ interactions in complexes where both interactions coexist. This interplay can lead to strong cooperativity effects. We have also demonstrated a similar behavior between $\mathrm{C}-\mathrm{H} / \pi$ and $\pi-\pi$ interactions [44] and between cation- $\pi$ and hydrogen bonding interactions [45] in pyrrole and indole 
complexes where the simultaneous interaction of the arene (i) with cations using the $\pi$-cloud of the aromatic ring and (ii) with water via hydrogen bonding using the $\mathrm{N}-\mathrm{H}$ group has an enhancing effect on both interactions. In this manuscript, we report a theoretical study on several polyhydroxysubstituted biphenyl and p-terphenyl moieties where one benzene ring has been replaced by either pyridine, pyrimidine or s-tetrazine ring, see Fig. (1). The binding features of compounds $\mathbf{1 - 5}$ have been compared with model compounds 6-11, see Fig. (2).

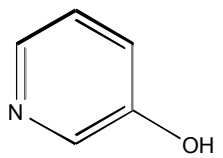

6<smiles>Oc1cc(O)ncn1</smiles>

9

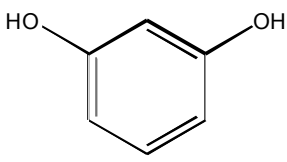

7<smiles>Oc1cc(O)c(O)cc1O</smiles>

10

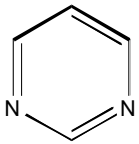

8<smiles>c1nncnn1</smiles>

11
Fig. (2). Model compounds 6-11.

\section{COMPUTATIONAL METHODS}

The geometries of all compounds and complexes studied in this work were fully optimized at the MP2/6-31++G** level of theory using the Gaussian-03 program [46]. The binding energies were calculated with correction for the basis set superposition error (BSSE) by using the BoysBernardi counterpoise technique [47]. The optimization of compounds 1-11 has been performed without imposing symmetry constrains. The optimization of the complexes of 2 with glycine has been performed imposing $C_{s}$ symmetry. Other possible conformations of complexes have not been considered because the ultimate aim of this study is to verify the interplay between both non covalent interactions and to obtain an insight into the nature of the cooperativity, therefore we have only concentrated on those complex geometries. The physical nature of the noncovalent interactions has been studied using the Molecular Interaction Potential with polarization (MIPp) [48] method. The MIPp is a convenient tool for predicting binding properties. It has been successfully used for rationalizing molecular interactions such as hydrogen bonding and ion- $\pi$ interactions and for predicting molecular reactivity [49-51]. The MIPp partition scheme is an improved generalization of the MEP where three terms contribute to the interaction energy, i) an electrostatic term identical to the MEP [52], ii) a classical dispersion-repulsion term [53], and iii) a polarization term derived from perturbational theory [54]. Some basic concepts of MIPp follow (see reference [48] for a more comprehensive treatment). The MEP can be understood as the interaction energy between the molecular charge distribution and a classical point charge. The formalism used to derive MEP remains valid for any classical charge, therefore it can be generalized using equation 1 where $Q_{B}$ is the classical point charge at $R_{B}$. $Q_{B}$ can adopt any value, but it has a chemical meaning only when $Q_{B}=1$ (proton), $\phi$ stands for the set of basis functions used for the quantum mechanical molecule $A$, $c_{\mu i}$ is the coefficient of atomic orbital $\mu$ in the molecular orbital $i$.

$$
M E P=\sum_{A} \frac{Z_{A} Q_{B}}{\left|R_{B}-R_{A}\right|}-\sum_{i}^{o c c} \sum_{\mu} \sum_{v} c_{\mu i} c_{v i}<\phi_{\mu}\left|\frac{Q_{B}}{\left|R_{B}-r\right|}\right| \phi_{v}>
$$

The MEP formalism permits the rigorous computation of the electrostatic interaction between any classical particle and the molecule. Nevertheless, nuclear repulsion and dispersion effects are omitted. This can be resolved by the addition of a classical dispersion-repulsion term, which leads to the definition of MIP (equation 2), where $C$ and $D$ are empirical van der Waals parameters.

$$
M I P=M E P+\sum_{A^{\prime} B^{\prime}}\left(\frac{C_{A^{\prime} B^{\prime}}}{\left|R_{B^{\prime}}-R_{A^{\prime}}\right|^{12}}-\frac{D_{A^{\prime} B^{\prime}}}{\left|R_{B^{\prime}}-R_{A^{\prime}}\right|^{6}}\right)
$$

The definition of MIPp is given by equation 3, where polarization effects are included at the second order perturbation level; $\varepsilon$ stands for the energy of virtual $(j)$ and occupied $(i)$ molecular orbitals. It is worth noting that equation 3 includes three important contributions: first, the rigorous calculation of electrostatic interactions between quantum mechanical and classical particles; second, the introduction of an empirical dispersion-repulsion term and third, the perturbative treatment of the polarization term.

$$
\left.M I P p=M I P+\sum_{j}^{v i r} \sum_{i}^{o c c} \frac{1}{\varepsilon_{i}-\varepsilon_{j}}\left\{\sum_{\mu} \sum_{v} c_{\mu i} c_{v i}<\phi_{\mu}\left|\frac{Q_{B}}{\left|R_{B}-r\right|}\right| \phi_{v}\right\rangle\right\}^{2}
$$

The MIPp has been computed at the HF/6$31++\mathrm{G}^{* *} / / \mathrm{MP} 2 / 6-31++\mathrm{G}^{* *}$ level of theory. The sodium cation has been considered as a classical non-polarizable particle, as is common in MIPp calculations [48].

\section{RESULTS AND DISCUSSION}

In Fig. (3) we show the MEP surfaces computed for $\mathbf{1}$ and 2 and the MEP values calculated over the center of the rings. It can be observed that in $\mathbf{1}$ the MEP value is -20.9 $\mathrm{kJ} / \mathrm{mol}$, and in the related model compound 3-hydroxypyridine 6 is $-36.4 \mathrm{~kJ} / \mathrm{mol}$. In compound 1 the 3 -hydroxypyridine moiety is participating in hydrogen bonding as acceptor and donor simultaneously and the global effect is a decrement in the absolute value of the MEP to $15.5 \mathrm{~kJ} / \mathrm{mol}$. An explanation for this result is that two opposite effects are operative in 1: i) the aromatic ring is acting as a H-bond acceptor via the nitrogen atom, increasing the electrondeficiency of the $\pi$-cloud of the aromatic ring; and ii) the aromatic ring is acting as a hydrogen bond donor via the hydroxyl group, increasing the electron richness of the $\pi$ cloud of the aromatic ring. The global effect, as deducted by the MEP values of $\mathbf{1}$ and $\mathbf{6}$, is an increase in the electron deficiency of the $\pi$-cloud of the aromatic rings of 1 . This is because the H-bond acceptor nitrogen atom belongs to the aromatic ring, whilst the $\mathrm{H}$-bond donor oxygen atom does not. Therefore the first aforementioned effect (increase of the electron deficiency) is more efficient than the second (in- 
crease in the electron richness). Moreover, the prediction and explanation of the global effect is still more complicated because in $\mathbf{1}$ each aromatic ring has, in addition to the hydrogen bond network, another ring conjugated, which also contributes to the electronic nature of the hydroxypyridine rings of $\mathbf{1}$. The behavior of compound 2 with respect to the model compounds resorcinol $\mathbf{7}$ and pyrimidine $\mathbf{8}$ is very interesting. The MEP value over the center of the pyrimidine ring in $\mathbf{2}$ is much more positive than the value in $\mathbf{8}$, indicating that the presence of two hydrogen bonds has a enormous effect on the $\pi$-binding ability of pyrimidine. In addition, the MEP value over the resorcinol ring is more negative (12.5 $\mathrm{kJ} / \mathrm{mol}$ ) in 2 than in 7, indicating a moderate effect on the resorcinol. As a consequence of the intramolecular hydrogen bonding in $\mathbf{2}$, an enhancement of the pyrimidine ring for the interaction with anions is observed and, at the same time, an enhancement for the interaction with cation over the resorcinol ring is also observed. Therefore, compound $\mathbf{2}$ can be seen as a potential ion-pair ditopic receptor.

To verify the hypothesis deduced from the aforementioned preliminary results obtained using the MEP calculations, we have computed a complex of $\mathbf{2}$ with the most simple amino acid, i.e. glycine in its zwitterionic form at the MP2/6-31++G** level of theory. Moreover, we have computed the same complex in a conformation where the intramolecular hydrogen bonds in $\mathbf{2}$ are not formed (see Fig. (4)). It can be observed that the location of the glycine amino acid depends on the presence/absence of intramolecular hydrogen bonding. In the conformation with hydrogen bonds, the positive part $\left(-\mathrm{NH}_{3}{ }^{+}\right)$mainly interacts with the resorcinol ring and the negative part $\left(-\mathrm{COO}^{-}\right)$with the pyrimidine ring. In the other conformation (absence of H-bonding), the geometry is totally different, and the amino acid is only located over the pyrimidine ring. A likely explanation for this migration is that the anion interacts more favorably with one hydrogen atom of the pyrimidine ring than with the $\pi$-cloud of pyrimidine ring in the absence of hydrogen bonding. It is worth mentioning that the quadrupole moment of pyrimidine $\left(\mathrm{Q}_{\mathrm{zz}}\right)$ perpendicular to the aromatic ring is negative $(-2.12 \mathrm{~B})$, therefore the pyrimidine ring is not enough $\pi$-acidic in the absence of hydrogen bonding. The computed binding energies are included in Fig. (4) and they indicate that the conformation where the hydrogen bonds are formed is more suitable for the zwitterionic recognition of glycine.

It has been demonstrated that the ion- $\pi$ interaction $[39,55,56]$ is equally dominated by polarization and electrostatic contributions. Therefore, we have extended our study to compounds 3-5 using the Molecular Interaction Potential with polarization (MIPp) method, see Fig. (5). We have computed the MIPp over the center of the rings in compounds 3-5 interacting with $\mathrm{Na}^{+}$and we have compared the partitioning of the interaction energies to those obtained for model compounds 7-11, see Fig. (6). In Fig. (5) and Fig. (6) we represent the optimized structures of the complexes and we include the computed value of the MIPp for the interaction with $\mathrm{Na}^{+}$over the center of the ring. It can be clearly observed that the MIPp values range from modest positive values $(+20.5 \mathrm{~kJ} / \mathrm{mol}$, in the central ring of 5) to significant negative values $(-176.4 \mathrm{~kJ} / \mathrm{mol}$ in the central ring of 4). For instance the MIPp value computed for resorcinol in $\mathbf{3}$ is $170.1 \mathrm{~kJ} / \mathrm{mol}$ and in 5 is $-115.0 \mathrm{~kJ} / \mathrm{mol}$. Furthermore, the value computed for pyrimidine in $\mathbf{3}$ is only $-2.5 \mathrm{~kJ} / \mathrm{mol}$, whilst in 4 is $-57.7 \mathrm{~kJ} / \mathrm{mol}$.

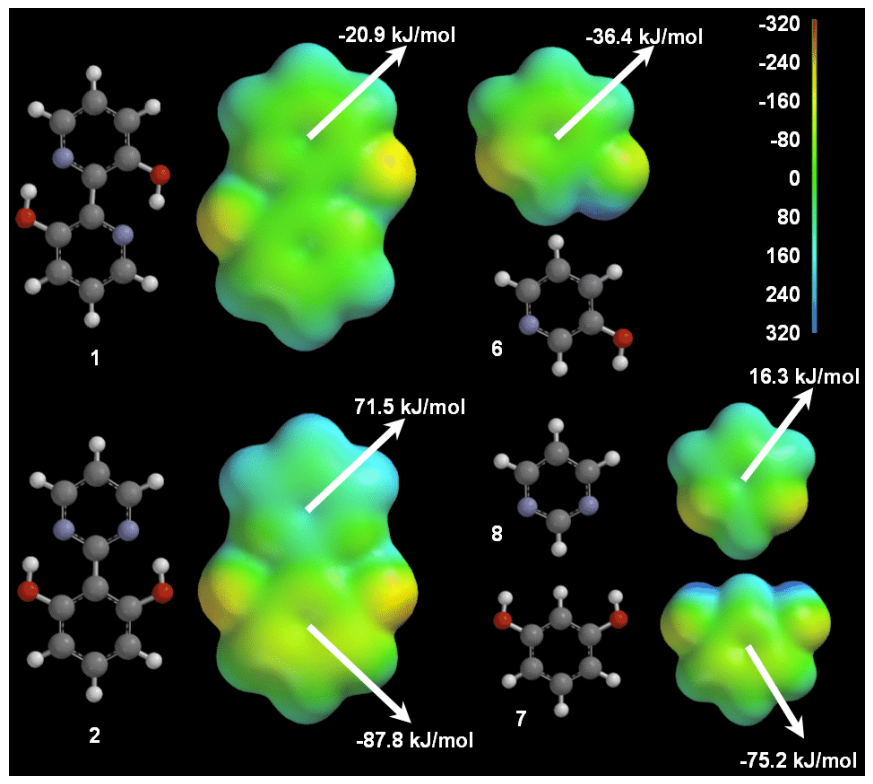

Fig. (3). Molecular electrostatic potential energy surfaces computed for compounds 1-2 and model compounds 6-8. Some representative MEP values computed over the center of the ring are shown.
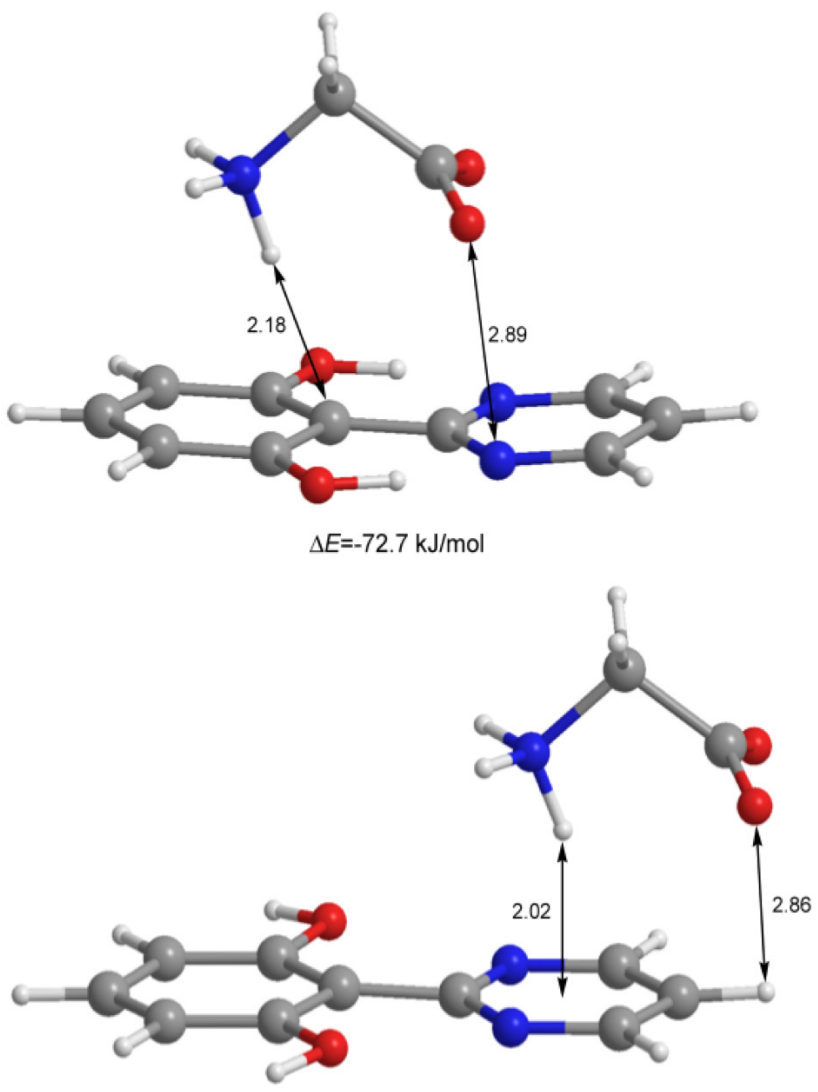

$\Delta E=-51.8 \mathrm{~kJ} / \mathrm{mol}$

Fig (4). MP2/6-31++G** optimized complexes of Glycine with 2. Distances are in $\AA$. 


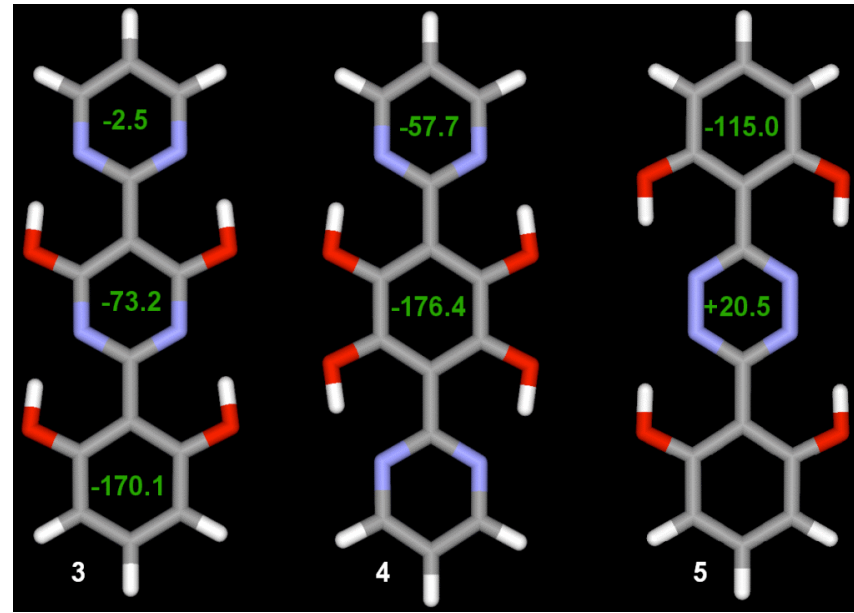

Fig (5). Molecular Interaction Potential with polarization (MIPp) energy values $(\mathrm{kJ} / \mathrm{mol})$ computed for the interaction of the aromatic compounds 3-5 with $\mathrm{Na}^{+}$at $2.2 \AA$ over the ring centroid.

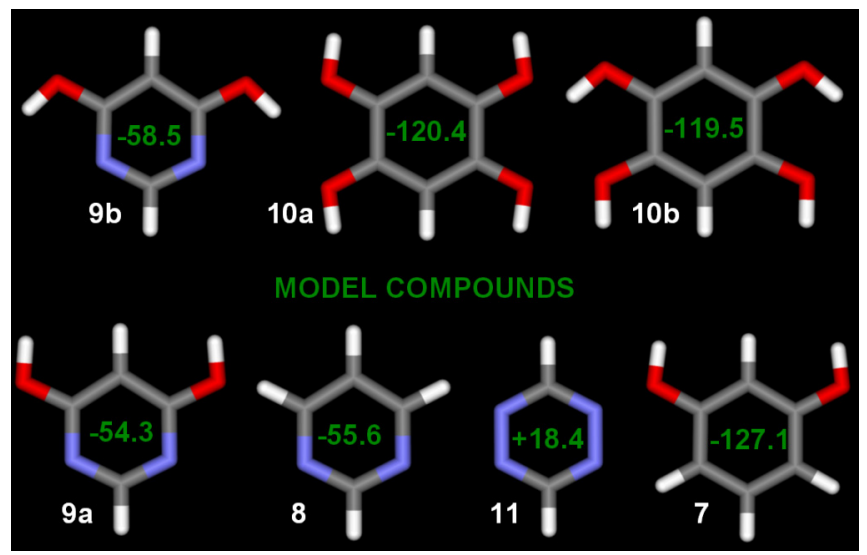

Fig. (6). Molecular Interaction Potential with polarization (MIPp) energy values $(\mathrm{kJ} / \mathrm{mol})$ computed for the interaction of the aromatic model compounds 7-11 in several conformations with $\mathrm{Na}^{+}$at $2.2 \AA$ over the ring centroid.

In Table 1, we summarize the contributions (electrostatic $E_{\mathrm{e}}$, polarization $E_{\mathrm{p}}$ and van der Waals $\left.E_{\mathrm{vw}}\right)$ to the total interaction energies of compounds 3-11 interacting with $\mathrm{Na}^{+}$. From the inspection of the results, several interesting points emerge. First, the polarization contribution $\left(E_{\mathrm{p}}\right)$ is very important in all compounds and in most cases dominates the interaction. It is more important in compounds 3-5 due to the extended aromatic systems. Second, we have explored in model compounds 9 and 10, two different conformations (a and $b$ ), depending on the orientation of the hydroxyl groups, see Fig. (6). In Table 1, we have included the MIPp values obtained for both orientations and the results are comparable, indicating that the orientation of the hydroxyl groups does not influence the MIPp values over the aromatic ring. Third, in compound $\mathbf{3}$ we observe that the hydrogen bond network considerably enhances the interaction energy of $\mathrm{Na}^{+}$with the resorcinol ring $(41.8 \mathrm{~kJ} / \mathrm{mol}$ more negative than 7$)$ and, in a more modest way, it also enhances the interaction of $\mathrm{Na}^{+}$ with the central ring. In contrast, the interaction of pyridimine with $\mathrm{Na}^{+}$is considerably reduced. This indicates that the participation of pyrimidine in hydrogen bonding as ac- ceptor reduces its cation- $\pi$ binding ability. Fourth, in 4 the central ring has an interaction energy significantly more negative than 10, indicating that the participation in hydrogen bonding as donor enhances the cation- $\pi$ interaction. In this compound, the MIPp value computed for the pyrimidine ring is $-57.7 \mathrm{~kJ} / \mathrm{mol}$, more negative than the value computed for $\mathbf{3}$, and in both cases it is participating in hydrogen bonding as acceptor. The partition scheme indicates that the difference is due to electrostatic effects. A probable explanation is that in $\mathbf{4}$, the electron rich tetrahydroxybenzene ring is donating electrons into the pyrimidine and thereby making it more receptive to $\mathrm{Na}^{+}$. Finally, in 5, the MIPp value at the central ring is very similar to the computed one for the model compound 11. In addition, the value computed at the resorcinol ring is less negative than the computed one for resorcinol 7. This fact can be explained by the influence of the electron-withdrawing substituted s-tetrazine, which is an electron-poor ring. These results confirm that the participation of the arenes in hydrogen bonding as donor enhances the cation- $\pi$ interaction. However this enhancement also depends upon the nature of the aromatic ring that is directly bonded, since it can either donate or withdraw electron density to the aromatic ring that is interacting with $\mathrm{Na}^{+}$.

Table 1. Contributions to the Total Interaction $\left(E_{t}\right)$ Energy (kJ/mol) Computed Using MIPp of Compounds 3-5 and 7-11 Interacting with $\mathrm{Na}^{+}$at $2.2 \AA$ from the Ring Centroid

\begin{tabular}{|c|c|c|c|c|}
\hline Compound & $\boldsymbol{E}_{\mathbf{e}}$ & $\boldsymbol{E}_{\mathbf{p}}$ & $\boldsymbol{E}_{\mathrm{vw}}$ & $\boldsymbol{E}_{\mathbf{t}}$ \\
\hline \hline 3 (central ring) & 27.6 & -112.0 & 11.3 & -73.2 \\
(pyrimidine ring) & 77.7 & -92.0 & 11.7 & -2.5 \\
(resorcinol ring) & -75.7 & -106.6 & 12.1 & -170.1 \\
\hline $\mathbf{4}$ (central ring) & -66.5 & -121.6 & 11.7 & -176.4 \\
(pyrimidine ring) & 25.9 & -95.3 & 11.7 & -57.7 \\
\hline $\mathbf{5}$ (central ring) & 109.9 & -99.9 & 10.5 & 20.5 \\
(resorcinol ring) & -21.7 & -105.8 & 12.5 & -115.0 \\
\hline $\mathbf{7}$ & -53.1 & -89.5 & 15.5 & -127.1 \\
\hline $\mathbf{8}$ & 2.5 & -71.1 & 13.0 & -55.6 \\
\hline $\mathbf{9 a}$ & 11.3 & -81.1 & 15.5 & -54.3 \\
\hline $\mathbf{9 b}$ & 6.7 & -80.7 & 15.5 & -58.5 \\
\hline $\mathbf{1 0 a}$ & -44.7 & -88.6 & 13.0 & -120.4 \\
\hline $\mathbf{1 0 b}$ & -44.3 & -88.2 & 13.0 & -119.5 \\
\hline $\mathbf{1 1}$ & 68.1 & -61.4 & 11.7 & 18.4 \\
\hline
\end{tabular}

\section{CONCLUSIONS}

In summary, the results reported in this manuscript stress the importance of non covalent interactions involving aromatic systems and the interplay among them, that can lead to strong cooperativity effects Due to the presence of a great number of aromatic rings containing heteroatoms in biological systems, this effect can be important in biological processes where the interplay between both interactions may ex- 
ist. It also should be taken into account in supramolecular chemistry and crystal engineering fields.

\section{ACKNOWLEDGMENT}

We thank the DGICYT of Spain and Govern Balear (projects CTQ2005-08989-01 and PROGECIB-33A, respectively) for financial support. We thank the Centre de Supercomputació de Catalunya (CESCA) for computational facilities. D. E. thanks "Fundació Sa Nostra" for a fellowship.

\section{REFERENCES}

[1] Lehn J-M. Supramolecular Chemistry-Concepts and Perspectives; VCH: Weinheim; 1995.

[2] Gale PA, Garcia-Garrido SE, Garric, J. Anion receptors based on organic frameworks: highlights from 2005 and 2006. Chem Soc Rev 2008; 37(1): 151-90.

[3] Meyer EA, Castellano RK, Diederich F. Interactions with aromatic rings in chemical and biological recognition. Angew Chem Int Ed 2003; 42(11): 1210-50.

[4] Mascal M, Armstrong A, Bartberger M. Anion-aromatic bonding: a case for anion recognition by $\pi$-acidic rings. J Am Chem Soc 2002; 124(22): 6274-6.

[5] Alkorta I, Rozas I, Elguero J. Interaction of anions with perfluoro aromatic compounds. J Am Chem Soc 2002; 124(29): 8593-8.

[6] Quiñonero D, Garau C, Rotger C, et al. Anion- $\pi$ interactions: do they exist?. Angew Chem Int Ed 2002; 41(18): 3389-92.

[7] Gamez P, Mooibroek TJ, Teat SJ, Reedijk J. Anion binding involving $\pi$-acidic heteroaromatic rings. Acc Chem Res 2007; 40(6): 43544.

[8] Schottel BL, Chifotides HT, Dunbar KR. Anion- $\pi$ interactions. Chem Soc Rev 2008; 37(1): 68-83.

[9] Demeshko S, Dechert S, Meyer F. Anion- $\pi$ Interactions in a Carousel Copper(II)-Triazine Complex. J Am Chem Soc 2004; 126(14): $4508-9$.

[10] Schottel BL, Bacsa J, Dunbar KR. Anion dependence of $\mathrm{Ag}(\mathrm{I})$ reactions with 3,6-bis(2-pyridyl)-1,2,4,5-tetrazine (bptz): isolation of the molecular propeller compound $\left[\mathrm{Ag}_{2}(\mathrm{bptz})_{3}\right]\left[\mathrm{AsF}_{6}\right]_{2}$ Chem Commun 2005; (1): 46-7.

[11] Rosokha YS, Lindeman SV, Rosokha SV, Kochi JK. Halide recognition through diagnostic "Anion- $\pi$ " interactions: molecular complexes of $\mathrm{Cl}^{-}, \mathrm{Br}^{-}$, and $\mathrm{I}^{-}$with olefinic and aromatic $\pi$ receptors. Angew Chem Int Ed 2004; 43(35): 4650-2.

[12] de Hoog P, Gamez P, Mutikainen I, Turpeinen U, Reedijk J. An aromatic anion receptor: anion- $\pi$ interactions do exist. Angew Chem Int Ed 2004; 43(43): 5815-17.

[13] Frontera A, Saczewski F, Gdaniec M, et al. Anion- $\pi$ interactions in cyanuric acids: a combined crystallographic and computational study. Chem Eur J 2005; 11(22): 6560-7.

[14] Albrecht M, Wessel C, de Groot M, Rissanen K, Lüchow A. Structural versatility of anion- $\pi$ interactions in halide salts with pentafluorophenyl substituted cations. J Am Chem Soc 2008; 130(14): 4600-1.

[15] Mooibroek TL, Black CA, Gamez P, Reedijk J. What's new in the realm of anion- $\pi$ binding interactions? putting the anion- $\pi$ interaction in perspective. Cryst Growth Des 2008; 8(4): 1082-93.

[16] Berryman OB, Bryantsev VS, Stay DP, Johnson DW, Hay BP. Structural criteria for the design of anion receptors: the interaction of halides with electron-deficient arenes. J Am Chem Soc 2007; 129(1): 48-58.

[17] Mascal M. Precedent and theory unite in the hypothesis of a highly selective fluoride receptor. Angew Chem Int Ed 2006; 45(18): 2890-3.

[18] Escudero D, Frontera A, Quiñonero D, Ballester P, Costa A, Deyà PM. Induced-polarization energy map: a helpful tool for predicting geometric features of anion- $\pi$ complexes. J Chem Theory Comput 2007; 3(6): 2098-107.

[19] Hay PB, Bryantsev VS. Anion-arene adducts: C-H hydrogen bonding, anion- $\pi$ interaction, and carbon bonding motifs. Chem Commun 2008.

[20] Mascal M, Yakovlev I, Nikitin EB, Fettinger JC. Fluoride-selective host based on anion- $\pi$ interactions, ion pairing, and hydrogen bond- ing: synthesis and fluoride-ion sandwich complex. Angew Chem Int Ed 2007; 46(46): 8782-4.

[21] Gorteau V, Bollot G, Mareda J, Perez-Velasco A, Matile S. Rigid oligonaphthalenediimide rods as transmembrane anion- $\pi$ slides. J Am Chem Soc 2006; 128(46): 14788-9.

[22] Gorteau V, Bollot G, Mareda J, Matile S. Rigid-rod anion- $\pi$ slides for multiion hopping across lipid bilayers. Org Biomol Chem 2007; 5(18): 3000-12.

[23] Schottel BL, Chifotides HT, Shatruk M, et al. Anion- $\pi$ interactions as controlling elements in self-assembly reactions of $\mathrm{Ag}(\mathrm{I}) \mathrm{com}$ plexes with $\pi$-acidic aromatic rings. J Am Chem Soc 2006; 128(17): 5895-912.

[24] Reger DL, Wayson RP, Smith MD. Silver(I) Complexes of fixed, polytopic bis(pyrazolyl)methane ligands: influence of ligand geometry on the formation of discrete metallacycles and coordination polymers. Inorg Chem 2006; 45(25): 10077-87.

[25] Zhou X-P, Zhang X, Lin S-H, Li D. Anion- $\pi$-interaction-directed self-assembly of $\mathrm{Ag}(\mathrm{I})$ coordination networks. Cryst Growth Des 2007; 7(3): 485-7.

[26] Steel J, Sumbly CJ. Coordination chemistry of di-2-pyridylmethane and related bridging ligands with silver(I), copper(II), palladium(II) and zinc(II). Dalton Trans 2003;(23): 4505-15.

[27] Domasevitch KV, Solntsev PV, Gural'skiy IA, et al. Silver(I) ions bridged by pyridazine: doubling the ligand functionality for the design of unusual 3D coordination frameworks. Dalton Trans 2007; 35: 3893-905.

[28] Black CA, Hanton LR, Spicer MD. A coordination polymer strategy for anion encapsulation: anion- $\pi$ interactions in $(4,4)$ nets formed from $\mathrm{Ag}(\mathrm{I})$ salts and a flexible pyrimidine ligand. Chem Commun 2007; 30: 3171-3.

[29] Ma JC, Dougherty DA. The cation- $\pi$ interaction. Chem Rev 1997; 97(5): 1303-24.

[30] Gallivan JP, Dougherty DA. Cation- $\pi$ interactions in structural biology. Proc Natl Acad Sci USA 1999; 96(17): 9459-64.

[31] Gokel GW, Wall SLD, Meadows ES. Experimental evidence for alkali metal cation- $\pi$ interactions. Eur J Org Chem 2000; 17: 296778.

[32] Gokel GW, Barbour LJ, Wall SLD, Meadows ES. Macrocyclic polyethers as probes to assess and understand alkali metal cation- $\pi$ interactions. Coord Chem Rev 2001; 222(1): 127-54.

[33] Gokel GW, Barbour LJ, Ferdani R, Hu J. Lariat ether receptor systems show experimental evidence for alkali metal cation-pi interactions. Acc Chem Res 2002; 35(10): 878-86.

[34] Hunter CA, Singh J, Thorton JM. $\pi-\pi$ interactions: the geometry and energetics of phenylalanine-phenylalanine interactions in proteins. J Mol Biol 1991; 218(4): 837-46.

[35] Kumpf RA, Dougherty DA. A mechanism for ion selectivity in potassium channels: computational studies of cation- $\pi$ interactions. Science 1993; 261(5129): 1708-10.

[36] Heginbotham L, Lu Z, Abramson T, Mackinnon R. Mutations in the $\mathrm{K}^{+}$channel signature sequence. Biophys J 1994; 66(4): 106176.

[37] Dougherty DA. Cation- $\pi$ interactions in chemistry and biology: a new view of benzene, Phe, Tyr, and Trp. Science 1996; 271(5246): 163-8.

[38] Lummis SCR, Beene DL, Harrison NJ, Lester HA, Dougherty DA. A cation- $\pi$ binding interaction with a tyrosine in the binding site of the GABA receptor. Chem Biol 2005; 12(9): 993-7.

[39] Cubero E, Luque FJ, Orozco M. Is polarization important in cation$\pi$ interactions? Proc Natl Acad Sci USA 1998; 95(11): 5976-80.

[40] Jeffrey GA. An Introduction to Hydrogen Bonding (Topics in Physical Chemistry). Oxford University Press, USA, 1997.

[41] Garcia-Raso A, Alberti FM, Fiol JJ, et al. Anion- $\pi$ interactions in bisadenine derivatives: a combined crystallographic and theoretical study. Inorg Chem 2007; 46(25): 10724-35.

[42] Frontera A, Quiñonero D, Costa A, Ballester P, Deyà PM. MP2 study of cooperative effects between cation- $\pi$, anion- $\pi$ and $\pi-\pi$ interactions. New J Chem 2007; 31(4): 556-60.

[43] Escudero D, Frontera A, Quiñonero D, Deyà PM. Interplay between anion- $\pi$ and hydrogen bonding interactions. J Comput Chem 2008.

[44] Quiñonero D, Frontera A, Escudero D, Ballester P, Costa A, Deyà PM. MP2 Study of synergistic effects between $\mathrm{X}-\mathrm{H} / \pi(\mathrm{X}=\mathrm{C}, \mathrm{N}, \mathrm{O})$ and $\pi-\pi$ interactions. Theor Chem Acc 2008. 
[45] Escudero D, Frontera A, Quiñonero D, Deyà PM. Interplay between cation- $\pi$ and hydrogen bonding interactions. Chem Phys Lett 2008; 456(4-6): 257-61.

[46] Frisch MJ, Truck GW, Schlegel HB, et al. Gaussian 03, Revision C.02. Gaussian Inc: Wallingford CT; 2003.

[47] Boys SB, Bernardi F. The calculation of small molecular interactions by the differences of separate total energies. Some procedures with reduced errors. Mol Phys 1970; 19(4): 553-66.

[48] Luque FJ, Orozco M. Polarization effects in generalized molecular interaction potential: new Hamiltonian for reactivity studies and mixed QM/MM calculations. J Comput Chem 1998; 19(8): 866-81.

[49] Hernández B, Orozco M, Luque FJ. Role of the tautomerism of 2 azaadenine and 2-azahypoxanthine in substrate recognition by xanthine oxidase. J Comput-Aided Mol Des 1997; 11(2): 153-62.

[50] Luque FJ, Orozco M. Reactivity of planar and twisted amides in vacuum and aqueous environments: an ab initio MEP study. J Chem Soc Perkin Trans 2 1993; 683-90.
[51] Quiñonero D, Frontera A, Garau C, Ballester P, Costa A, Deyà PM. Interplay Between Cation- $\pi$, Anion- $\pi$ and $\pi-\pi$ Interactions. ChemPhysChem 2006; 7(12): 2487.

[52] Scrocco E, Tomasi J. The electrostatic molecular potential as a tool for the interpretation of molecular properties. Top Curr Chem 1973; 42: 95-170.

[53] Orozco M, Luque FJ. Molecular interaction potential: A new tool for the theoretical study of molecular reactivity. J Comput Chem 1993; 14(5): 587-602.

[54] Francl MM. Polarization corrections to electrostatic potentials. J Phys Chem 1985; 89(3): 428-34.

[55] Garau C, Frontera A, Quiñonero D, Ballester P, Costa A, Deyà PM. a topological analysis of the electron. density in anion- $\pi$ interactions. ChemPhysChem 2003; 4(12): 1344-8.

[56] Garau C, Frontera A, Quiñonero D, Ballester $\mathrm{P}$, Costa A, Deyà PM. Cation- $\pi$ versus anion- $\pi$ interactions: energetic, charge transfer, and aromatic aspects. J Phys Chem A 2004; 108(43): 9423-7.

(C) Quiñonero et al.; Licensee Bentham Open.

This is an open access article distributed under the terms of the Creative Commons Attribution License (http://creativecommons.org/licenses/by/2.5/), which permits unrestrictive use, distribution, and reproduction in any medium, provided the original work is properly cited. 